\title{
New records of the damsel bug Alloeorhynchus reinhardi Kerzhner \& Günther, 1999 (Hemiptera, Heteroptera, Nabidae) from Japan
}

\author{
Jun Souma ${ }^{1,2^{*}}$, Tatsuya Nozaki ${ }^{3}$, Keiichi Otsui $^{3}$, Tadashi Ishikawa ${ }^{4}$ \\ 1 Entomological Laboratory, Graduate School of Bioresource and Bioenvironmental Sciences, Kyushu University, Fukuoka, Japan - JS: \\ kodokusignal@gmail.com (Dttps://orcid.org/0000-0002-2238-5015 \\ 2 Research Fellowship for Young Scientists (DC1), Japan Society for the Promotion of Science, Tokyo, Japan \\ 3 Kyushu Branch Office, Wesco Co., Ltd., Fukuoka, Japan・TN: t-nozaki@wesco.co.jp•KO: k-otsui@wesco.co.jp \\ 4 Laboratory of Entomology, Faculty of Agriculture, Tokyo University of Agriculture, Kanagawa, Japan • TI: chuishikawa@gmail.com \\ * Corresponding author
}

\begin{abstract}
To date, the damsel bug Alloeorhynchus reinhardi Kerzhner \& Günther, 1999 (Hemiptera, Heteroptera, Nabidae, Prostemmatinae, Prostemmatini) has been reported from China and Korea. We report from Japan for the first time $A$. reinhardi, which represents the second member of the genus in the country. This species inhabits the ground surface of grasslands in Kyushu.
\end{abstract}

Keywords

East Asia, Kyushu, Palaearctic Region, Prostemmatinae, Prostemmatini

Academic editor: Hélcio Gil-Santana | Received 3 February 2022 | Accepted 25 February 2022 | Published 8 March 2021

Citation: Souma J, Nozaki T, Otsui K, Ishikawa T (2022) New records of the damsel bug Alloeorhynchus reinhardi Kerzhner \& Günther, 1999 (Hemiptera, Heteroptera, Nabidae) from Japan. Check List 18 (2): 261-264. https://doi.org/10.15560/18.2.261

\section{Introduction}

The damsel bug Alloeorhynchus reinhardi Kerzhner \& Günther, 1999 (Hemiptera, Heteroptera, Nabidae, Prostemmatinae, Prostemmatini), which has macropterous and brachypterous morphs, has been recorded in China and Korea (Kerzhner and Günther 1999; Gapon and Konstantinov 2008; Aukema et al. 2013; Zhao et al. 2019; Lee et al. 2020). However, in Japan, only one species of the genus Alloeorhynchus Fieber, 1860, A. vinulus Stål, 1864, has been recorded to date (Miyamoto 1964; Ishikawa 2016).

For the past 13 years, two of us (TN and KO), together with other colleagues, have collected an indeterminate species of Alloeorhynchus from Kyushu, Japan. After careful morphological examination, we concluded that it corresponds to $A$. reinhardi. Thus, we report here $A$. reinhardi from Japan for the first time as the second member of the genus in the country.

\section{Methods}

Dried specimens were used for observing morphological characteristics. For the examination of the genitalia, the male terminalia were removed from the body after softening the specimens in hot water. The removed parts were immersed in hot $15 \% \mathrm{KOH}$ solution for $5 \mathrm{~min}$ and then soaked in $99 \%$ ethanol for further observation. The male genitalia were preserved in small polyethylene vials containing $50 \%$ glycerin and mounted on a pin with the respective specimens. Morphological characteristics were observed and measured under a stereoscopic 
microscope (SZ60; Olympus, Tokyo, Japan) equipped with an ocular grid. The specimens were photographed using a digital microscope (Dino-Lite Premier M, Opto Science, Tokyo, Japan), and image stacks were processed using Adobe Photoshop 2021 v. 22.5.1.

All specimens used in this study were deposited in the Entomological Laboratory, Faculty of Agriculture, Kyushu University, Fukuoka, Japan (ELKU) and the Laboratory of Entomology, Faculty of Agriculture, Tokyo University of Agriculture, Kanagawa, Japan (TUA).

Distribution records of species were mapped using SimpleMappr (Shorthouse 2010). Geographical coordinates were obtained using Google Maps. The map was edited using Adobe Photoshop 2021 v. 22.5.1.

\section{Results}

Alloeorhynchus reinhardi is herein recorded from Japan for the first time based on 11 macropterous specimens collected from Kyushu, representing the second member of the genus in the country.
Alloeorhynchus reinhardi Kerzhner \& Günther, 1999 Figures 1-3

New records. JAPAN - Kyushu - Fukuoka-ken, Fukuoka-shi, Nishi-ku, Motooka, Kyushu University, Ito Campus, Biodiversity Zone; 333' $43.9^{\prime \prime} \mathrm{N}, 130^{\circ} 12^{\prime} 53.1^{\prime \prime}$ E; 27.IV.2020; Tsubasa Nozaki leg.; macropterous 1 q ELKU • Fukuoka-ken, Fukuoka-shi, Nishi-ku, Motooka, Kyushu University, Ito Campus; $33^{\circ} 35^{\prime} 50.3^{\prime \prime} \mathrm{N}$ $130^{\circ} 12^{\prime} 52.4^{\prime \prime} \mathrm{E}$; in litter; 8.XI.2021; Naomichi Tsuji leg.; macropterous 1 ઈ ELKU • Nagasaki-ken, Nagasaki-shi; $32^{\circ} 47^{\prime} 40.4^{\prime \prime} \mathrm{N} 129^{\circ} 52^{\prime} 16.9^{\prime \prime} \mathrm{E}$; 13.X.2013; Tatsuya Nozaki leg.; macropterous 1 ô, 1 q TUA • Oita-ken, Nakatsu-shi, Yabakei-machi, Oshima, Yabakei Dam;3326'49.4"N $131^{\circ}$ 07'26.6"E; 16-17.V.2008; Takeshi Miyake leg.; macropterous 1 q TUA • Oita-ken, Hita-shi, Mt. Shakagatake, Tsubakigahana; $33^{\circ} 11^{\prime} 04.6^{\prime \prime} \mathrm{N} \mathrm{130} 0^{\circ} 54^{\prime} 13.8^{\prime \prime} \mathrm{E}$; alt. $900 \mathrm{~m}$; highland grassland; 12.IX.2019; Tatsuya Nozaki \& Keiichi Otsui leg.; macropterous 1 \& TUA • as above but 19.X.2019; macropterous 1 ô, 4 q TUA.

Differential diagnosis. Alloeorhynchus reinhardi is easily distinguished from the other Japanese species of the
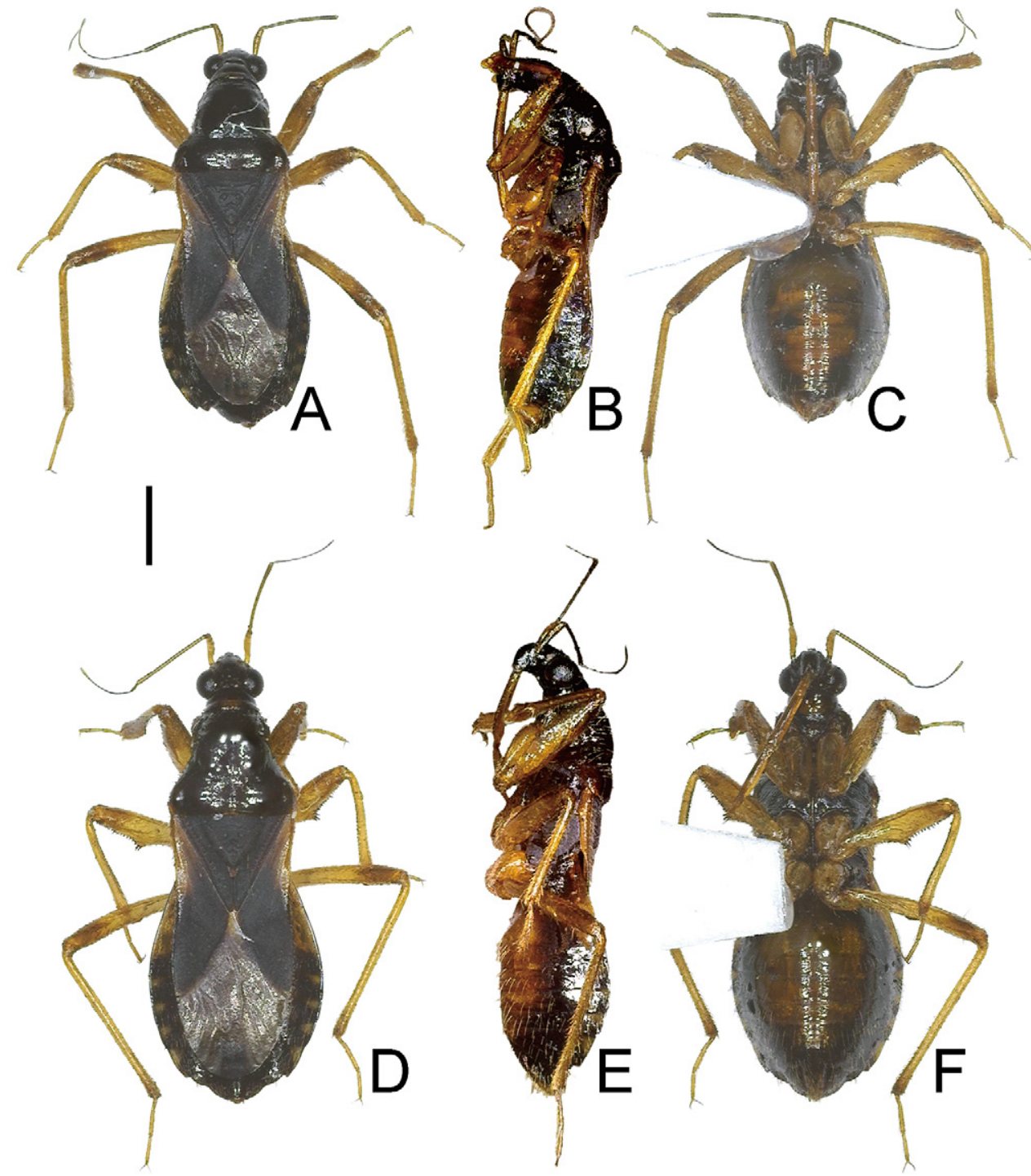

Figure 1. Dried specimens of Alloeorhynchus reinhardi from Fukuoka, Kyushu, Japan. A. Male, dorsal view. B. Male, lateral view. C. Male, ventral view. D. Female, dorsal view. E. Female, lateral view. F. Female, ventral view. Scale bar: $1.0 \mathrm{~mm}$. 


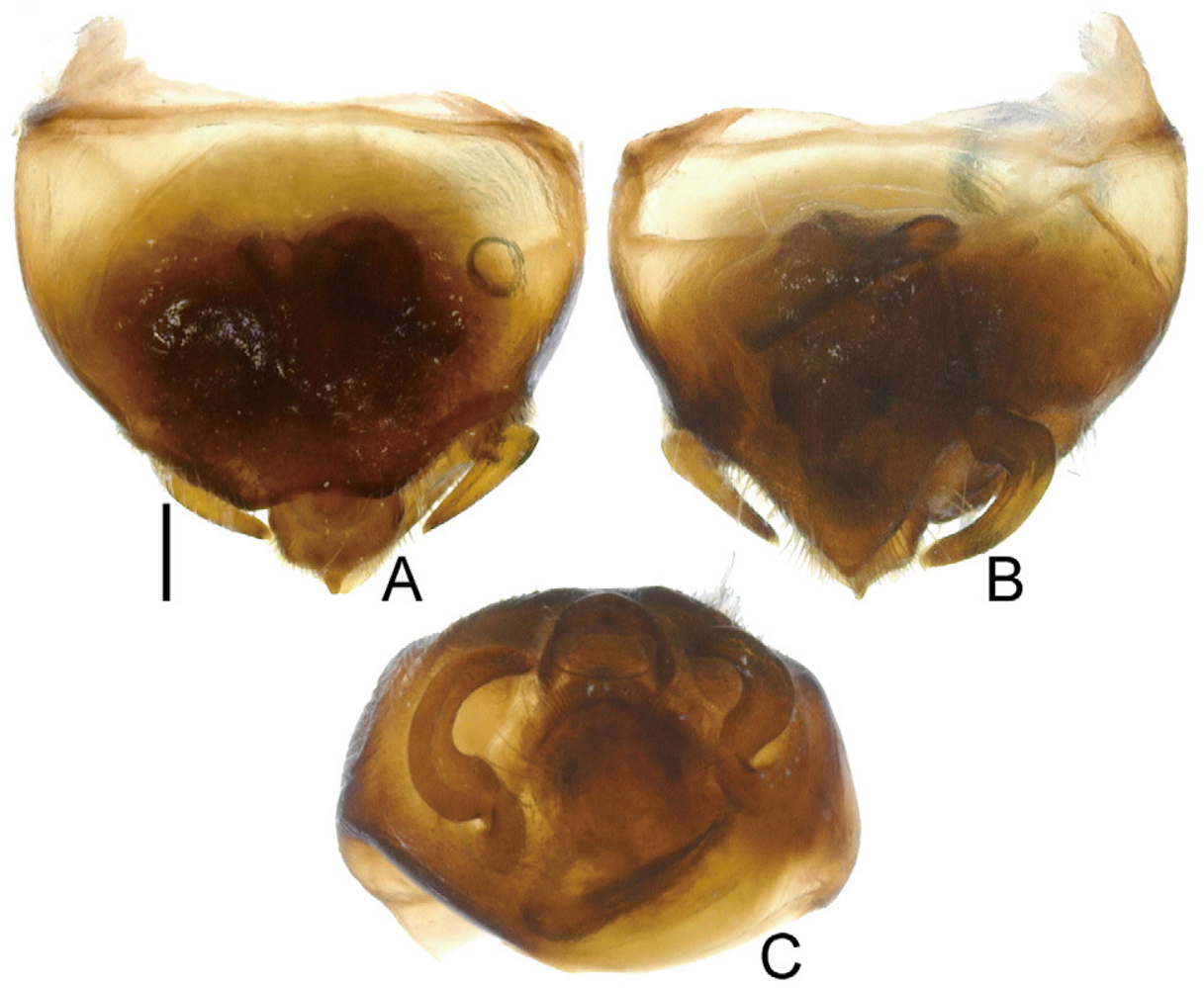

Figure 2. Pygophore of Alloeorhynchus reinhardi. A. Dorsal view. B. Ventral view. C. Posterior view. Scale bar: 0.2 mm.

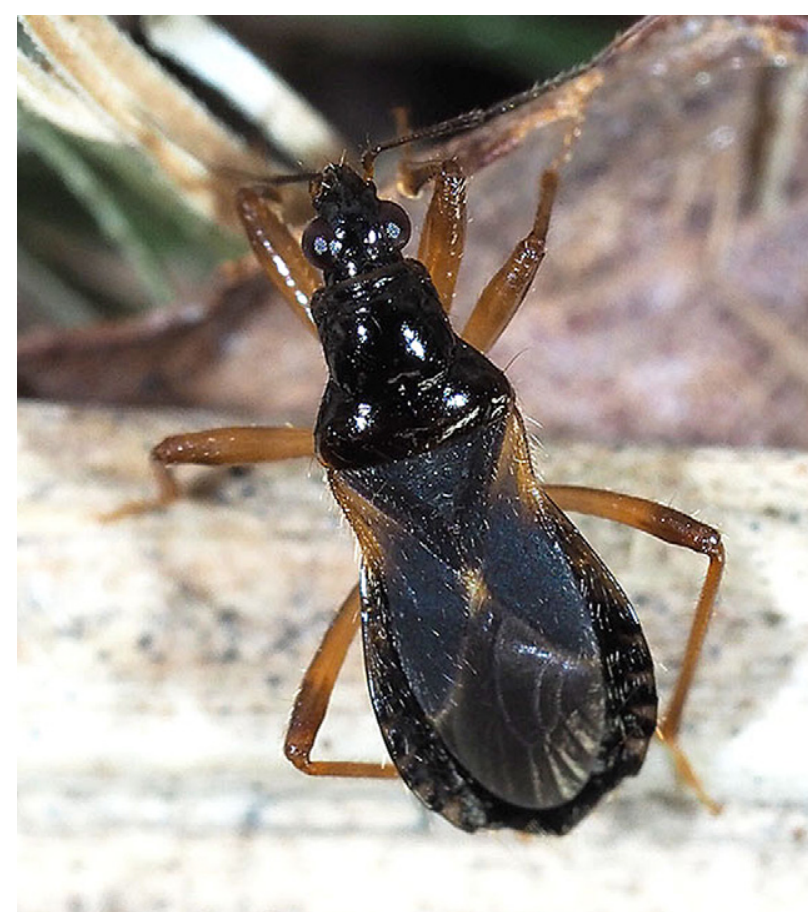

Figure 3. Photograph of a living adult of Alloeorhynchus reinhardi from Oita, Kyushu, Japan.

genus, A. vinulus, by the black anterior pronotal lobe and the dark brown basal part of the hemelytral corium (Fig. 1).

Identification. All 11 specimens recorded above (Figs. 1-3) match well the descriptions of the macropterous morphs of $A$. reinhardi in terms of morphological characteristics (Zhao et al. 2019; Lee et al. 2020), including the photographs of male genitalia (Lee et al. 2020).
Moreover, these specimens can be identified as A. reinhardi using the key including all East Asian species of Alloeorhynchus (Zhao et al. 2019). Therefore, we identified the above-recorded specimens as $A$. reinhardi.

Distribution. Japan (Kyushu), China (Guizhou Province, Sichuan Province), and Korea (South Chungcheong Province) (Fig. 4).

Biology. Alloeorhynchus reinhardi occurs on the ground surface of grasslands in Kyushu, Japan (present study) and in Korea has been found in moist places near streams, particularly on piles or clusters of dead leaves of Cyperaceae spp. under plants (Lee et al. 2020). Adults were collected from March to November (Kerzhner and Günther 1999; Zhao et al. 2019; Lee et al. 2020; present study). The nymph is unknown.

\section{Discussion}

Alloeorhynchus reinhardi has only been recorded from two localities in China and one locality in Korea to date (Kerzhner and Günther 1999; Zhao et al. 2019; Lee et al. 2020). Therefore, our report of $A$. reinhardi from Kyushu, Japan, represents the easternmost occurrences of this species (Fig. 4). Moreover, the localities in Japan and the type locality (China; westernmost record) are at least $2,900 \mathrm{~km}$ apart, whereas the Korean locality (northernmost record) and another locality in China (southernmost record) are more than 2,200 km apart. Therefore, this damsel bug species seems to be widely distributed in East Asia, and more localities will probably be discovered in future field surveys.

The Japanese population of $A$. reinhardi has the black 


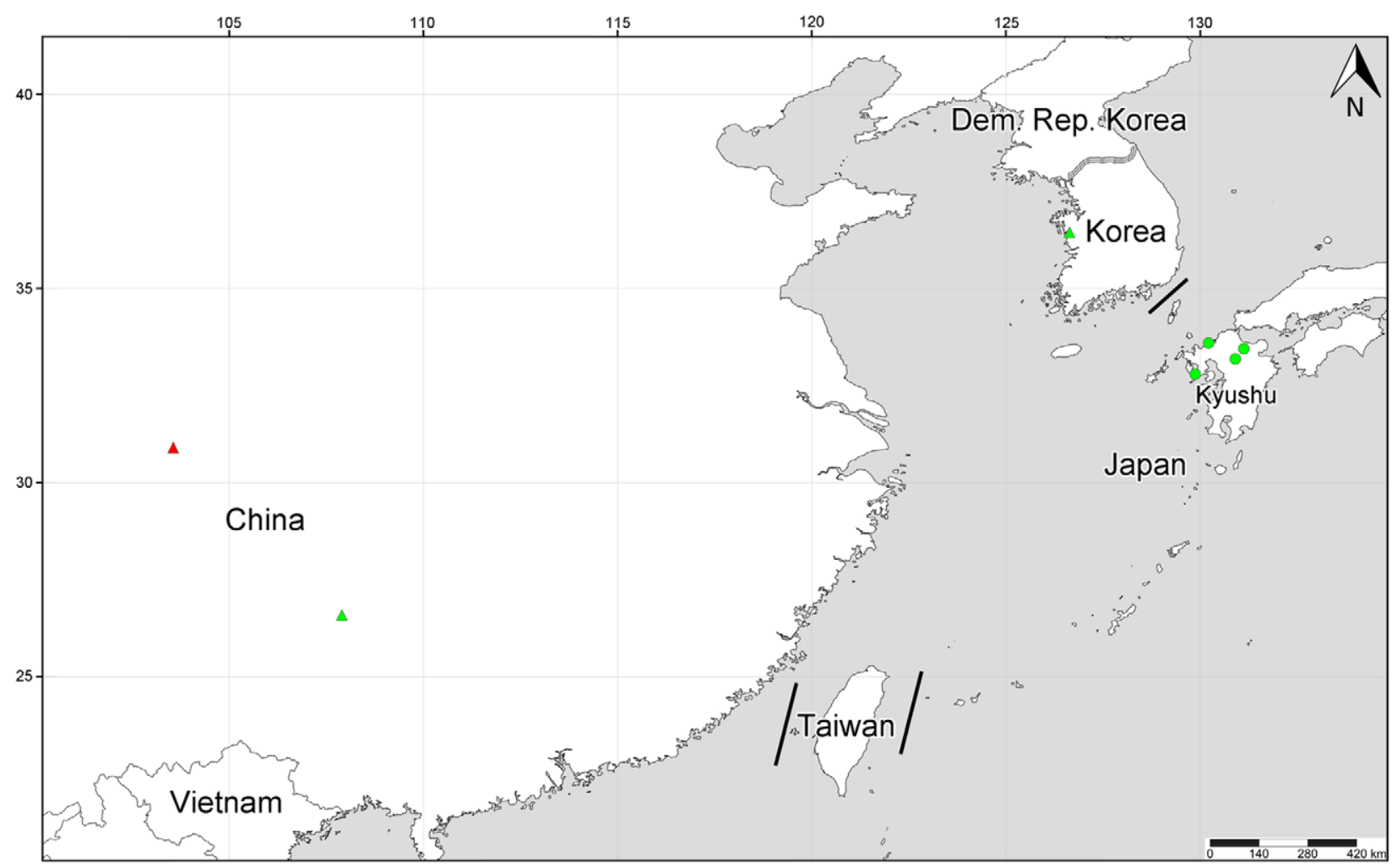

Figure 4. Collection sites of Alloeorhynchus reinhardi. Red icon = type locality; green icons = other localities. Circles = new records; triangles $=$ known records.

pronotum and the dark brown basal part of the hemelytral corium (Fig. 3), whereas the Chinese and Korean populations have the dark brown pronotum and the pale brown basal part of the hemelytral corium (Zhao et al. 2019; Lee et al. 2020). These differences in coloration are considered to be geographical variations, suggesting that the genetic interaction between the continental (China and Korea) and island (Kyushu, Japan) populations have not occurred for a long time.

\section{Acknowledgements}

We express our sincere thanks to Hélcio R. Gil-Santana (Instituto Oswaldo Cruz, Rio de Janeiro, Brazil) and the three anonymous reviewers for critical comment to the manuscript. We are grateful to Takeshi Miyake (Oita, Japan), Naomichi Tsuji, and Tsubasa Nozaki (ELKU) for kindly providing valuable materials and information on the collection sites. This work was partially supported by a Grant-in-Aid for JSPS Fellows (JP20J20483) to the first author from the Japan Society for the Promotion of Science, Tokyo, Japan. We would like to thank Editage (https://www.editage.jp) for English language editing.

\section{Author Contributions}

Data curation: TN, KO. Funding acquisition: JS. Investigation: TN, KO. Methodology: JS. Project administration: TI, JS. Software: JS. Supervision: TI, JS. Validation:
JS. Visualization: JS. Writing - original draft: JS. Writing - review and editing: JS, TI.

\section{References}

Aukema B, Rieger C, Rabitsch W (2013) Catalogue of the Heteroptera of the Palaearctic Region. Vol. 6, supplement. The Netherlands Entomological Society, Amsterdam, the Netherlands, xxiv $+629 \mathrm{pp}$.

Gapon DA, Konstantinov EV (2008) Taxa of Heteroptera described by Izyaslav M. Kerzhner. Zoosystematica Rossica 17: 24-36.

Ishikawa T (2016) Family Nabidae. In: Hayashi M, Tomokuni M, Yoshizawa K, Ishikawa T (Eds.) Catalogue of the insects of Japan, Volume 4, Paraneoptera. Touka-shobo, Fukuoka, 436-439 [in Japanese].

Kerzhner IM, Günther H (1999) Eine neue Alloeorhynchus-Art aus Süd-China (Hemiptera: Heteroptera: Nabidae). Reichenbachia 33: 221-225.

Lee H, Kim J, Lim J, Jung S (2020) Taxonomic review of the subfamily Prostemmatinae (Hemiptera: Heteroptera: Cimicomorpha: Nabidae) from the Korean Peninsula. Journal of Asia-Pacific Biodiversity 13 (1): 29-34. https://doi.org/10.1016/j.japb.2019.10.005

Miyamoto S (1964) Tingidae and Nabidae of the south-west islands, lying between Kyushu and Formosa (Hemiptera). Kontyû 32 (2): 271-280.

Shorthouse DP (2010) SimpleMappr, an online tool to produce publication-quality point maps. http://www.simplemappr.net. Accessed: 2022-1-13.

Zhao P, Mao R, Cao L (2019) Two new and one little-known damsel bug of the subfamily Prostemmatinae Reuter (Hemiptera, Heteroptera, Nabidae) from China. ZooKeys 845: 139-152. https://doi. org/10.3897/zookeys.845.32893 